\title{
Complex assessment of athletes' operative status and its correction during competitions, based on the body impedance analysis
}

\author{
Olena Dorofieieva $^{1 \mathrm{ACDE}}$, Kseniia Yarymbash ${ }^{1 \mathrm{ABCDE}}$, Iryna Skrypchenko ${ }^{2 \mathrm{CDE}}$, Marko Joksimović ${ }^{3 \mathrm{CD}}$, Aneliia Mytsak ${ }^{4 \mathrm{AB}}$
}

${ }^{1}$ O.Bogomolets National Medical University, Ukraine

${ }^{2}$ Dnipropetrovs'k State University of Internal Affairs, Ukraine

${ }^{3}$ Football Club National, Montenegro

${ }^{4}$ Prydniprovsk State Academy of Physical Culture and Sports, Ukraine

Authors' Contribution: A - Study design; B - Data collection; C - Statistical analysis; D - Manuscript Preparation; E - Funds Collection

\begin{abstract}
Purpose: $\quad$ The aim of this research was assessment and correction of highly skilled swimmers' operative status during competitions.

Material: $\quad$ The authors carried out complex assessment of 46 high-skilled swimmers during competition period. The body impedance analysis and functional status express diagnosis were conducted before and after competitions.

Results: $\quad$ The components limiting the operational state of swimmers were determined: "component composition of the body" (44.83\% of the total load), "functional" (19.97\%). Correlation relationships were established between the main indicators that determine the level of the operational state of athletes. The multiple regression equation was calculated, which made it possible to determine the influence of individual significant parameters on the level of the operational state of athletes and the confidence interval. A group of athletes with operational status indicators below the confidence interval received sport supplementation.

Conclusions: The main characteristics of the athletes' operative status are cellular biomarker phase, fat free mass, extracellular water, intracellular water, strength index. These characteristics should be used in assessment of both operative status and complex functional diagnosis of highly-skilled swimmers during competitions.

Keywords: operative status, correction, body impedance analysis, highly skilled swimmers.
\end{abstract}

\section{Introduction}

The duration of competitions and number of competition days directly depends on the kind of sport. Swimming is the second after track and field athletics sport kind by the number of award medals. In the XXXI Olympiad of 2016 athletes participated in 32 kinds of swimming competitions. So, duration of swimming competitions ranges from 7 to 9 days. The winner results differ in centiseconds. Many athletes participate in several swimming distance types, which predisposes for increased requirements to their training, physical working performance and rehabilitation. This is why control and assessment of their operative status during all competitions is important for both timely correction and achieving best sport results. The method of body impedance analysis has recently been widely used in complex examination of athletes, which aids in evaluation of the athlete body composition changes, hydration and energy level during various stages of training. This provides for perfection of the competition trainings, loading intensity, i.e. effectively and timely improve athlete condition before the competitions [1-4]. There have been carried out sufficient number of the body impedance analyses of athlete during training [5-8]. The relation between body impedance characteristics and physical ability to work as

\footnotetext{
(c) Olena Dorofieieva, KseniiaYarymbash, Iryna Skrypchenko,

Marko Joksimović, Aneliia Mytsak, 2021

doi:10.15561/26649837.2021.0201
}

well as preparation level have been revealed. Some studies have been held in cyclic sport types [9-11]. However, none of the studies revealed practice application of the body impedance analysis during competitions. There are still no data on the effect of certain characteristics onto the person's sport performance as well as necessity of timely correction of the athletes' operative status at the start in swimming. The aim of this research was assessment and correction of highly skilled swimmers' operative status during competitions.

\section{Materials and methods}

Participants

46 athletes of the National swimming team of Ukraine have participated in the study, aged from 17 to 23 years $(20 \pm 3.2)$. All participants agreed on their data processing and publication of the study results. In order to assess the operation status of highly-skilled swimmers several tests have been held within the study:

$>$ Multi-factorial express-diagnosis according to Dushanin [17], aimed at estimating functional condition due to the anaerobic metabolism threshold heart rate (ANMT HR), maximum oxygen consumption (MOC), total metabolic capacity (TMC), creatine phosphate (CP).

> Variation pulsometry according to Baievskiy [17], detecting the tension index (TI). 
> Body impedance analysis (Bioscan Touch8) of the following characteristics: cellular biomarker phase (CBP), fat free mass (FFM), fat mass (FM), body density (BD), extracellular water (ECW), intracellular water (ICW), Muscle mass (MM), extracellular mass (ECM), intracellular mass (ICM), strength index (SI), health index (HI), fitness score (FS).

Study design

The studies were held during the Licensing Winter Championship of Ukraine in Swimming. The athletes' operative status was assessed during all competition days. The first study was held in the day of athlete arrival, in order to detect the significant characteristics for calculating the multiple linear regression as well as confidence interval (critical data for assessment of the operation status dynamic pattern). The subsequent assessment of operation status was carried out in the morning and evening, before and after preliminary and final races on chosen distance during a day. According to the results of the survey, all athletes were divided into 2 groups. The athletes, whose characteristics exceeded confidence interval (R.L. Neuman [17]) (second group), underwent correction procedures. In order to improve the characteristics, the $2^{\text {nd }}$ group athletes took sport supplementation - Micellar Casein by company Nutrent (45 g Micellar Casein mixed with $300 \mathrm{ml}$ of water) before bedtime. The Micellar Casein basis is represented with milk protein isolate high in micellar casein, enriched with milk serum protein. The milk serum protein provides for enhanced rehabilitation (quick aminoacid balancing), and the level is supported during night by prolonged breakdown of micellar casein. Micellar Casein is also enriched with the probiotic and prebiotic complex LactoWise ${ }^{\mathrm{TM}}$. The probiotics (bacterium strain Bacillus coagulans) and prebiotics (bacterium strain Galactomannans) composing the LactoWise ${ }^{\mathrm{TM}}$ positively affect gastrointestinal functions.

Statistical Analysis

All obtained data were statistically processed using the STATISTIKA 10.0 software. The data are represented as the mean average \pm standard deviation (SD). The Fisher test was used to check standard distribution of the variables. In case of non-standard distribution, logarithmic transformation was used. The bilateral repeated estimation by STATISTIKA 10.0 was used for comparison of the obtained characteristics before the onset and in the end of the study. The relation between basic characteristics of function status was estimated using the Brave-Pearson correlation coefficient. To make a model of optimum operation status multiple linear regression equation was used, which aided in detecting the most significant parameters, providing for the best sport performance.

\section{Results}

To calculate the multiple linear regression in order to detect the most significant characteristics which show the swimmer's condition, factor analysis of the athletes' operation status structure was conducted. The study revealed 4 factors which completely reflect the highlyskilled swimmers operation status, with the first factor reflecting $44.83 \%$ of overall load, the second factor $19.97 \%$, the third factor- $13.7 \%$ and the fourth factor $112 \%$ (table 1).The first and second factors are the main in the dispersion, being the leading ones in detecting operation status of athlete.

The first factor, «body composition», consisted of 9 components - CBP, FFM, ECW, ICW, MM, ECM, ICM,

Table 1. Factor structure of operation status of highly skilled swimmers

\begin{tabular}{lllll}
\hline Variable & Factor $\mathbf{1}$ & Factor $\mathbf{2}$ & Factor 3 & Factor 4 \\
\hline Anaerobic metabolism threshold heart rate & -0.269523 & -0.943685 & 0.081395 & -0.018397 \\
Maximum oxygen consumption & -0.204162 & -0.952172 & 0.128614 & -0.041784 \\
Detecting the tension index & 0.109558 & -0.043541 & 0.944119 & -0.072216 \\
Total metabolic capacity & -0.119290 & 0.217078 & 0.108833 & 0.848637 \\
Creatine phosphate & -0.054539 & -0.655495 & 0.742335 & -0.079314 \\
Cellular biomarker phase & -0.979173 & 0.026677 & -0.016626 & -0.230020 \\
Fat free mass & -0.974103 & 0.173664 & 0.125126 & -0.212133 \\
Fat mass & 0.934969 & -0.173232 & -0.125654 & 0.208733 \\
Extracellular water & -0.953013 & -0.076487 & -0.187605 & -0.041514 \\
Intracellular water & 0.834177 & -0.393846 & -0.224038 & -0.060263 \\
Muscle mass & -0.840674 & 0.375749 & 0.272208 & 0.055290 \\
Extracellular mass & -0.961170 & -0.019385 & -0.135626 & 0.025915 \\
Intracellular mass & -0.845954 & -0.219844 & -0.341937 & 0.087828 \\
Strength index & -0.893531 & -0.305576 & 0.027535 & 0.544199 \\
Operative status & 0.047627 & 0.556781 & 0.423843 & -0.495383 \\
Total \% & 44.8369 & 19.9718 & 13.7490 & 11.2782 \\
\hline
\end{tabular}


SI. The maximum factor loading (0.97) observed with the FFM and CBP characteristics, which reflect functional condition of active muscular and fat tissue as well as the metabolism rate. The second factor, the «functional» one, joined two components of MOC and ANMT HR, which characterize special working performance of the swimmers. Maximum loading of the factor is observed with ANMT HR (0.95). The third factor joined two components: CP and TI. The maximum factor loading observed with the $\mathrm{CP}$ characteristics (0.94). The fourth factor is represented with a single parameter of TMC of 0.84 .To choose the most significant characteristic changes, which define the operation status level, the authors detected reliable relation between the obtained parameters (fig.1).

According to the received correlations, multiple linear regression equation was calculated, which provided for detection of certain significant characteristics reflecting the sport performance of the athlete:

$$
\text { OS }=1,78 \mathrm{X}_{10}+1,49 \mathrm{X}_{7}+0,932 \mathrm{X}_{11}+0,866 \mathrm{X}_{6}+0,466 \mathrm{X}_{15}-178,29
$$

where:

$\mathbf{O S}$ - operative status; $\mathbf{X}_{10}-\mathrm{ECW}$ - extracellular water; $\mathbf{X}_{7}-$ FFM - fat free mass; $\mathbf{X}_{11}-$ ICW - intracellular water; $\mathbf{X}_{6}-\mathrm{CBP}-$ cellular biomarker phase; $\mathbf{X}_{15}-\mathrm{SI}-$ strength index.
According to the results of the primary study, all athletes were characterized with high and "better than average" operation status. To assess the operation status dynamic pattern the authors calculated confidence interval, which equalled 2.67 units. The examination of 46 athletes in the end of the first competition day established two athletes groups. The changes of operation status in first group, represented with 35 athletes $(76.09 \%)$, didn't exceed the confidence interval limits. Decreased characteristics of FFM, ECW, ICW, SI and CBP were within tolerance, being closer to the initial ones after the morning and evening start. The operation status criteria in the second group, represented with 11 people (23.91\%) were considerably under the confidence interval limits after the morning start and after the final (table 2).

Maximum decrease observed in the FFM characteristics, which evidences about decreased dry muscle mass as well as energy supply SI, which is indicative of decreased power potential of the athletes, CBP, i.e. observed working performance and metabolism intensity. The decrease in these parameters coincides with decreased operation status of the second group athletes. Repeated assessment of the $1^{\text {st }}$ and $2^{\text {nd }}$ group athletes was conducted the next day, before the competitions. An increase in the second group athletes' operative status was noted, being almost similar with the initial one (Fig.2).

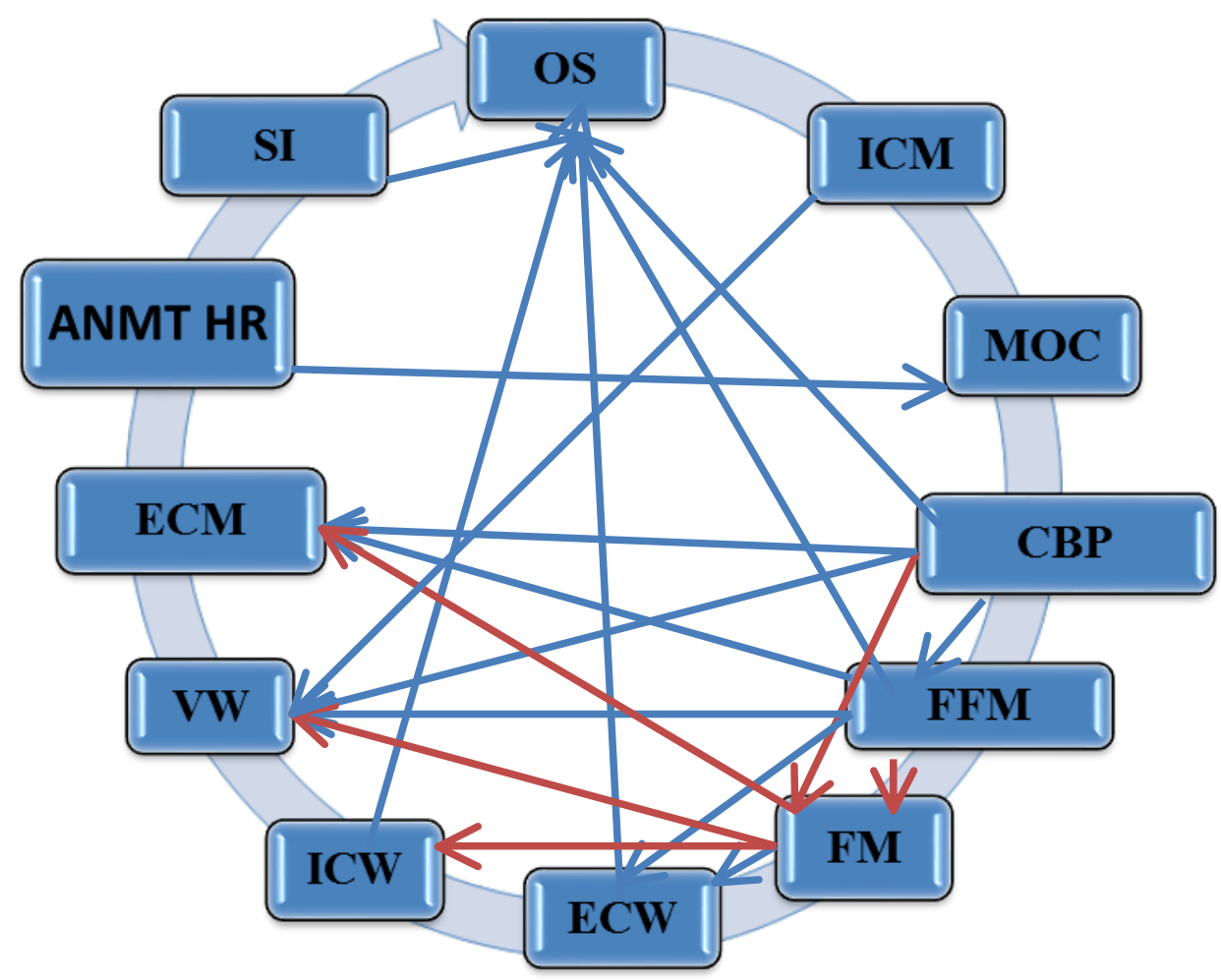

Figure 1. Correlation between the characteristics of sport performance of highly skilled swimmers during competitions.

Note: $\longrightarrow$ positive correlation; $\longrightarrow$ negative correlation; OS - operative status; SI - strength index; ANMT HR - anaerobic metabolism threshold heart rate; ECM - extracellular mass; VW - ; ICW - intracellular water; ECW extracellular water; FM - fat mass; FFM - fat free mass; CBP - cellular biomarker phase; MOC - maximum oxygen consumption; ICM - intracellular mass. 


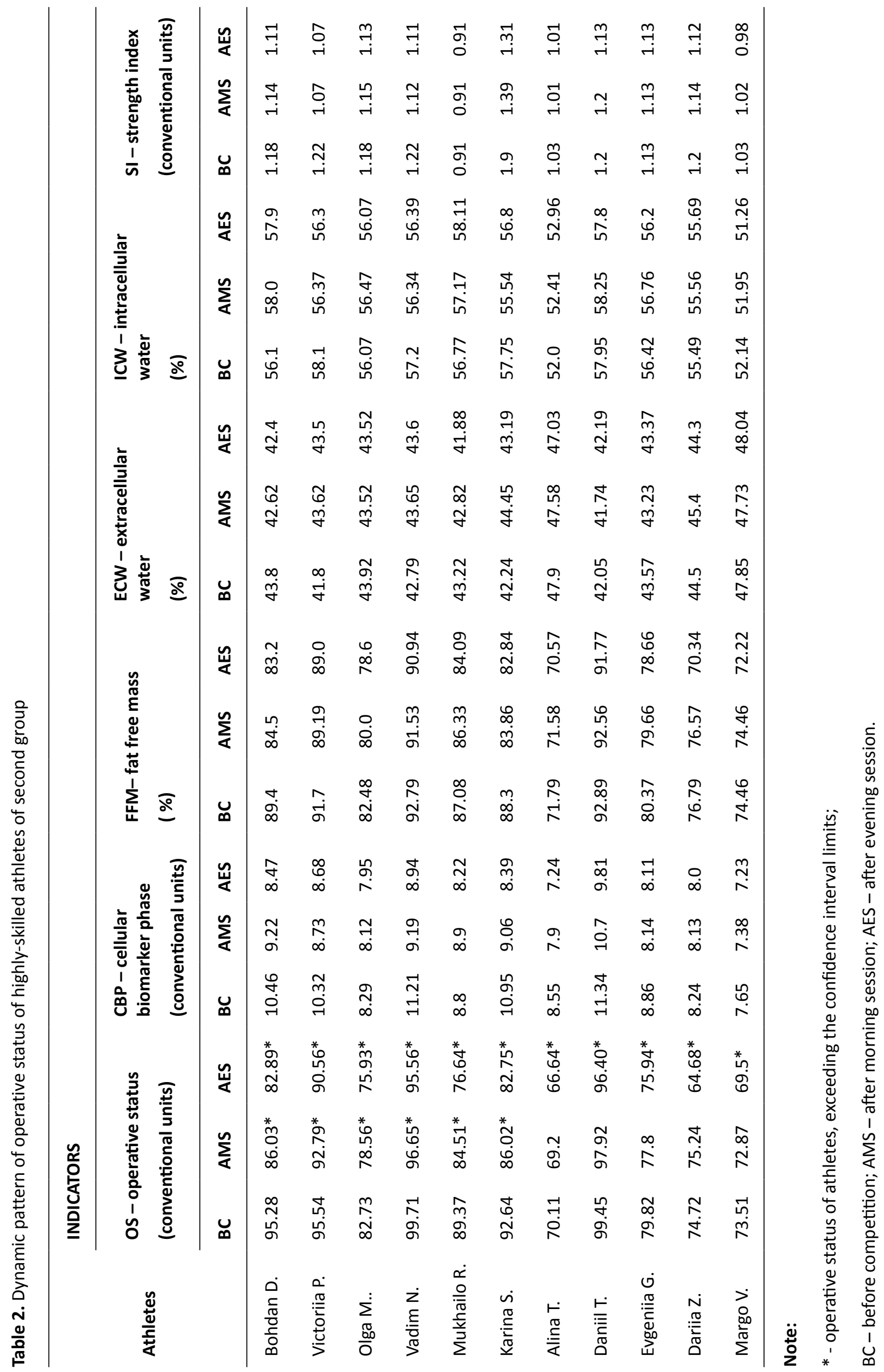




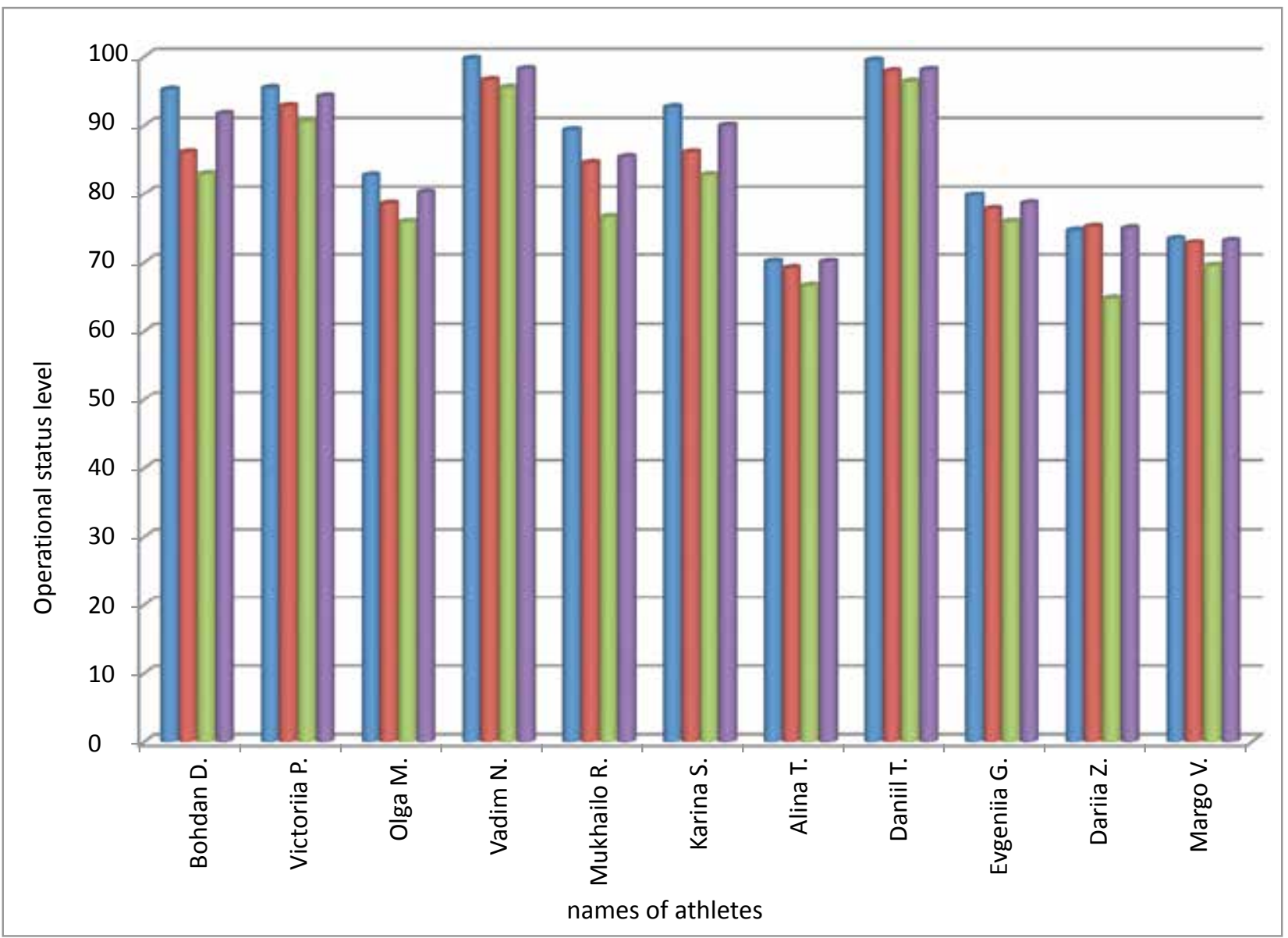

$\square$ - before competition competition; $\square$ - after morning session; $\square$ - after evening session; $\square$ - next morning before

Figure 2. Dynamic pattern of the highly skilled second group swimmers' operation status changes.

\section{Discussion}

The importance of the athletes' operation status as a leading factor in high sport performance is doubtless. The offered study includes assessment and correction of the athletes' operation status during the competitions, which was based on the multi-factorial express- diagnosis of functional condition, variation pulsometry and body impedance analysis. According to the received data, the multiple linear regression equation was calculated as well as the most significant characteristics of the body impedance analysis were detected. As far as the authors know, this is the first study, based on the factor, correlation and regression analysis aimed at completing the model of highly skilled swimmers' competition operation status model. Gutiérrez et al. [18] studied the body mass indicators of athletes and determined their role in assessing the preparedness of athletes. Malá et al. [5] conducted a systematic review and identified prospects for the future in the use of bio-impedance analysis in sport and exercise. Campa et al. [19] in his studies established a specific profile of an athlete according to the characteristics of body composition: FFM, EBW, FM, which completely coincides with our studies. Esco et al. [20] determined the accuracy of bioimpedance analysis to predict body composition in athletes. The significance of FFM was reassessed as one of the main factors in predicting body composition, which is also confirmed by our studies. Koury et al. [21, 22] used the bio-impedance analysis method to assess the functional state of young athletes in conditions of training based on the dynamics of FFM, and a conclusion was made about the need to take into account gender differences. It is proved that FFM can be a marker for determining the level of preparedness. CBP vectors were also determined, as a result of which a significant difference was found in the performance of qualified and unskilled athletes. The results of our studies have confirmed that FFM can be one of the main markers in assessing the operational state, and it was also proved that the FU index depends on the level of the athletes' operational state. Bešlija et al. [23] created a model for classifying athletes according to their level of preparedness based on bio-impedance indicators. Sesbreno et al. [24] monitored body composition and determined its relationship with performance, developed anthropometric models for assessing FFM and ACM, which allows us to determine the workability of athletes based on these indicators. In our studies, these indicators were identified as markers in assessing the performance 
of swimmers. Marini et al. [25] developed an individual approach to sports training and determined the main criteria for the effectiveness of the training process of athletes using bio-impedance analysis based on the phase angle index. A high correlation (effects) of FM, FFM, TBW, ICW was obtained, which indicates more accurate indicators of bioimpedance. It was also proven that $\mathrm{CBP}$ shows changes in the ratio of ECW and ICW under the influence of physical activity. In our studies, a high correlation relationship between these indicators was also determined. Sukach et al. [16], Veitia et al. [26] investigated the features of the component composition of the body of young athletes in cyclic sports and its impact on the level of performance. Higher CBP values (7.2-7.5) were determined, as well as compliance with the age norm of BMI, FFM indicators. Our studies also confirm the data obtained; higher CBP indicators were noted with an increase in the qualifications of athletes. Tinsley et al. [27] in his studies examined the FFM indicator and conducted a comparative analysis of its effect on the performance of athletes with an atypical physique. In our studies, the FFM indicator was considered as an indicator of improving sportsmanship and the performance of highly qualified athletes. Khafzova et al. [4] in their studies showed the importance of bioimpedance for assessing the adequacy of the applied loads, predicting sports results and the possibility of their use as selection criteria for sports. Our studies confirm the data. Komarova [11] in her studies determined the effect of the FFM, ACM, ECW, ICW indicators on bioimpedance and also confirmed that the indicators of this analysis are markers of a sports form and testify to the effectiveness of building the training process. In our studies, it was determined that FFM, ICW, ICW, SI, CBP are the main brokers in diagnosing the level of operational status of highly qualified swimmers in the conditions of competitive activity, which partially confirms the results of Komarova research. Meleleo et al. [28] evaluated muscle and fat mass, hydration of young athletes. It was determined that the BIA provides reliable information on competitive athletes based on the progression of ECW, ICW, CBP, FFM, FM and the less significant impact of TBW. We confirmed these data in studies with highly qualified swimmers in the conditions of competitive activity. Nickerson et al. [29], the change in VIA indicators was reliably confirmed depending on the level of sportsmanship, which is confirmed by our research. Silva [7] examined the structural and functional components of the body of athletes in the phenotype of sports health and performance based on the BIA. An integrative model has been proposed that links performance, risk of injury and athletic health. In these studies, it was determined that the performance of FM, FFM, ICW, ECW affect the level of fitness and the performance of athletes. Our results fully confirm these data, but in the conditions of competitive activity of highly qualified swimmers. Sonksen [30] used bio-impedance analysis to evaluate the performance of sports activities. The significance of these studies is confirmed by our data. Segal [6] in his studies showed the importance of the BIA on the basis of the ECW, ICW, FFM indicators in assessing the clinical status of athletes at risk of hydration disorders, indicated the need for certain correction tools. In our studies, these indicators were examined from the point of view of assessing the operational status and performance; on the basis of the identified changes, specific means of correcting these indicators were also proposed, which expands and partially confirms the research of Segal. An important factor for the study is defining significant criteria for the high skilled swimmers' operation status correction during competitions: calculating the confidence interval. Despite the obtained results, it is necessary to note that the importance of physical, technical and tactical readiness for achieving high results in swimming still stays high.

\section{Conclusions}

The basic criteria, determining the athletes' operation status, are CBP, FFM, ECW, ICW, SI. According to high reliability of the obtained results, these characteristics must be used for assessment of both operation status and complex functional diagnosis of high-skilled swimmers during competitions.

\section{Funding}

This research received no external funding.

\section{Acknowledgments}

We would like to thank the athletes for their enthusiastic participation in the study.

\section{Conflicts of interest}

Authors have no conflict of interest to declare. 


\section{References}

1. Castizo Olier J. Bioelectrical impedance vector analysis (BIVA) in exercise and sports practice (Doctoral dissertation). Universitat de Barcelona; 2018.

2. Castizo-Olier J, Irurtia A, Jemni M, Carrasco-Marginet M, Fernández-García R, Rodríguez FA. Bioelectrical impedance vectoranalysis(BIVA)in sportand exercise: Systematic review and future perspectives. PLOS ONE, 2018; 13(6): e0197957. https://doi.org/10.1371/journal.pone.0197957

3. Di Vincenzo O, Marra M, Scalfi L. Bioelectrical impedance phase angle in sport: a systematic review. Journal of the International Society of Sports Nutrition, 2019; 16(1): 49. https://doi.org/10.1186/s12970-019-0319-2

4. Khafzova GN, Gubaydullina SI, Asmanov RF. Body composition of the athletes playing sports. Science and Sport: Modern Tendencies, 2018; 3(20): 35 -40.

5. Malá L,ZahálkaF, Maly T. Bioimpedance for Analysis ofBody Composition in Sports. In: Simini F, Bertemes-Filho P, editors. Bioimpedance in Biomedical Applications and Research. Cham: Springer International Publishing; 2018. P. 243-56. https://doi.org/10.1007/978-3-319-74388-2_12

6. Segal KR. Use of bioelectrical impedance analysis measurements as an evaluation for participating in sports. The American Journal of Clinical Nutrition, 1996;64(3):469-471. https://doi.org/10.1093/ajen/64.3.469S

7. Silva Analiza M. Structural and Functional Body Components in Athletic Health and Performance Phenotypes. European Journal of Clinical Nutrition, 2018; 73(2): 215 -224. https://doi.org/10.1038/s41430-018-0321-9

8. Carrasco-Marginet M, Castizo-Olier J, RodríguezZamora L, Iglesias X, Rodríguez FA, Chaverri D, Irurtia A. Bioelectrical impedance vector analysis (BIVA) for measuring the hydration status in young elite synchronized swimmers. PLOS ONE, 2017; 12(6,7): e0178819. https://doi.org/10.1371/journal.pone.0178819

9. De Lorenzo A, Bertini I, Iacopino L, Pagliato E, Testolin C, Testolin G. Body composition measurement in highly trained male athletes. A comparison of three methods. Journal of Sports Medicine and Physical Fitness, 2000; 40(2): 178 -83.

10.Huygens W, Claessens AL, Thomis M, Loos R, Van Langendonck L, Peeters M, Philippaerts R, Meynaerts E, Vlietinck R, Beunen G. Body composition estimations by BIA versus anthropometric equations in body builders and other power athletes. Journal of Sports Medicine and Physical Fitness, 2002; 42(1): $45-55$.

11.Komarova AV. Research of Criteria of Training Process Effectiveness of Sportswomen with the Help of BioImpedance Analysis. Scholarly Notes, 2014; 6 (59): 55 -60.

12. Marra M, Da Prat B, Montagnese C, Caldara A, Sammarco R, Pasanisi F, Corsetti R. Segmental bioimpedance analysis in professional cyclists during a three week stage race. Physiological Measurement, 2016; 37(7): $1035-40$. https://doi.org/10.1088/0967-3334/37/7/1035

13. Melchiorri G, Viero V, Sorge R, Triossi T, Campagna A, Volpe S L, Andreoli A. Body composition analysis to study long-term training effects in elite male water polo athletes. Journal of Sports Medicine and Physical Fitness, 2018; 58(9): $1269-1274$

14.Arroyo-Toledo JJ, Clemente VJ, González-Rave JM. The effects of ten weeks block and reverse periodization training on swimming performance and body composition of moderately trained female swimmers. Journal of Swimming Research, 2013; 21(1): $1-13$.

15.Dave P, Subhedar R, Mishra P, Sharma D. Body composition parameter changes among young male and female competitive swimmers and nonswimmers. International Journal of
Medical Science and Public Health, 2015; 5(1): 1 -8. https://doi.org/10.5455/ijmsph.2016.2905201520

16. Sukach ES, Budko LA. Body composition of young athletes engaged in cyclic sports. Health problems and ecology, 2018; 1(55): $83-87$.

17.Miller LL. Sports Medicine. Moscow: Men; 2015. (In Russian)

18.Gutiérrez R, Aldea L, Cavia Mdel M, Alonso-Torre SR. Relation between the body composition and the sports practice in teenagers. Nutrición Hospitalaria, 2015; 32(1): 336 -45. https://doi.org/10.3305/nh.2015.32.1.9112

19.Campa, F.; Toselli, S. Bioimpedance Vector Analysis of Elite, Subelite, and Low-Level Male Volleyball Players. International Journal of Sports Physiology and Performance, 2018; 13(9): $1250-1253$. https://doi.org/10.1123/ijspp.2018-0039

20.Esco MR, Olson MS, Williford HN, Lizana SN, Russell AR. The accuracy of hand-to-hand bioelectrical impedance analysis in predicting body composition in college-age female athletes. Journal of Strength and Conditioning Research, 2011; 25(4): $1040-5$. https://doi.org/10.1519/JSC.0b013e3181cc224a

21.Koury JC, Trugo NMF, Torres AG. Phase angle and bioelectrical impedance vectors in adolescent and adult male athletes. International Journal of Sports Physiology and Performance, 2014; 9(5): 798 -804. https://doi.org/10.1123/ijspp.2013-0397

22.Koury JC, Ribeiro MA, Massarani FA, Vieira F, Marini E. Fat-free mass in adolescent athletes: Accuracy of bioimpedance equations and identification of new predictive equations. Nutrition, 2019; 60: $59-65$. https://doi.org/10.1016/j.nut.2018.09.029

23.Bešlija T, Čular D, Kezić A, Tomljanović M, Ardigò LP, Dhabhi W, Padulo J. Height-based model for the categorization of athletes in combat sports. European Journal of Sport Science, 2020; 1 -10. https://doi.org/10.1080/17461391.2020.1744735

24.Sesbreno E, Slater G, Mountjoy M, Galloway SDR. Development of an Anthropometric Prediction Model for Fat-Free Mass and Muscle Mass in Elite Athletes. International Journal of Sport Nutrition and Exercise Metabolism, 2020;30:174-81. https://doi.org/10.1123/ijsnem.2019-0232

25.Marini E, Campa F, Buffa R, Stagi S, Matias CN, Toselli S, Silva AM. Phase angle and bioelectrical impedance vector analysis in the evaluation of body composition in athletes. Clinical Nutrition, 2020; 39(2): 447 - 454. https://doi.org/10.1016/j.clnu.2019.02.016

26. Veitia WC, Campo YD, García IME, Chavez DA, Gutiérrez LRE, Cordova A. Body composition analysis using bioelectrical parameters in the Cuban sporting population. Arch Med, 2017; 34: 207 -215.

27. Tinsley GM, Graybeal AJ, Moore ML, Nickerson BS. Fat-free Mass Characteristics of Muscular PhysiqueAthletes. Medicine \& Science in Sports \& Exercise, 2019; 51(1): 193 -201. https://doi.org/10.1249/MSS.0000000000001749

28. Meleleo D, Bartolomeo N, Cassano L, Nitti A, Susca G, Mastrototaro G, Armenise U, Zito A, Devito F, Scicchitano P, Ciccone MM. Evaluation of body composition with bioimpedence. A comparison between athletic and non-athletic children. European Journal of Sport Science, 2017; 17(6): $710-719$. https://doi.org/10.1080/17461391.2017.1291750

29.Nickerson BS, Esco MR, Kliszczewicz BM, Freeborn TJ. Comparison of Bioimpedance and Underwater Weighing Body Fat Percentage Before and Acutely 
After Exercise at Varying Intensities. Journal of Strength and Conditioning Research, 2017; 31(5): 1395 -1402. https://doi.org/10.1519/JSC.0000000000001716
30.Sonksen P. Determination and regulation of body composition in elite athletes. British Journal of Sports Medicine, 2018; 52(4):219 -229. https://doi.org/10.1136/bjsports-2016-096742

\section{Information about the authors:}

Olena Dorofieieva; https://orcid.org/0000-0002-2028-6064; dorofeyevaelena@gmail.com; O.Bogomolets National Medical University; Kiev, Ukraine.

Kseniia Yarymbash; https://orcid.org/0000-0003-4694-291X; yarembash90@gmail.com; O.Bogomolets National Medical University; Kiev, Ukraine.

Iryna Skrypchenko; http://orcid.org/0000-0001-5895-3099; sit71@ukr.net; Dnipropetrovs'k State University of Internal Affairs; Dnipro, Ukraine.

Marko Joksimović; (Corresponding Author); http://orcid.org/0000-0003-4232-5033; nicifor007@outlook.com; Football Club Nacional; Podgorica, Montenegro.

Aneliia Mytsak; http://orcid.org/0000-0001-7965-8101; anelv26@ukr.net; Prydniprovsk State Academy of Physical Culture and Sports; Dnipro, Ukraine.

Cite this article as:

Dorofieieva O, Yarymbash K, Skrypchenko I, Joksimović M, Mytsak A. Complex assessment of athletes' operative status and its correction during competitions, based on the body impedance analysis. Pedagogy of Physical Culture and Sports, 2021;25(1):66-73.

https://doi.org/10.15561/26649837.2021.0201

This is an Open Access article distributed under the terms of the Creative Commons Attribution License, which permits unrestricted use, distribution, and reproduction in any medium, provided the original work is properly cited (http://creativecommons.org/licenses/by/4.0/deed.en).

Received: 02.07.2020

Accepted: 13.08.2020; Published: 25.02.2021 